\title{
ИНТОНАЦИОННЫЕ ГРУППЫ СОВРЕМЕННОГО ЧЕЧЕНСКОГО И АНГЛИЙСКОГО ЛИТЕРАТУРНЫХ ЯЗЫКОВ: СОПОСТАВИТЕЛЬНЫЙ АСПЕКТ
}

\section{COMPARATIVE STUDY OF INTONATION GROUPS OF THE MODERN CHECHEN AND ENGLISH LITERARY LANGUAGES}

T. Alkhastova

Summary: The present paper is a continuation of comparative and typological phonetical studies of the Chechen language. The purpose of the article was to determine differences and similarities in intonation groups of Chechen and English languages using the Praat computer program. For the first time the comparative analysis of syntagms of the modern Chechen and English literary languages is carried out on the example of spectrograms of narrative, interrogative, motivational, and exclamation sentences. Typological similarities and differences of rhythmic - intonation groups of the Chechen (source) and English (target) languages are established.

The obtained data will contribute to the correct assimilation of English intonation by Chechen speakers; it can become the basis for further development of Chechen and Nakh linguistics, in general.

Keywords: Chechen, English, intonation group, Praat, spectogram, speech melody, comparative studies.
$\mathrm{H}$ астоящая статья является продолжением сопоставительно-типологического исследования чеченского языка в области фонетики.

Цель работы состояла в том, чтобы провести сопоставительный анализ интонационных групп (синтагм) современного чеченского литературного языка, относящегося к нахской группе, иберийско-кавказской семье языков и современного английского литературного языка, относящегося к германской группе, индоевропейской семье языков.

Задачи - установить типологические сходства и различия ритмико-интонационных групп чеченского (исходного) и английского (целевого) языков на примере повествовательных, вопросительных, побудительных и восклицательных предложений.

Для решения указанных задач был использован преимущественно сопоставительный метод, включающий наблюдение, сопоставление и обобщение, а также спектральный компьютерный анализ.

\author{
Алхастова Таита Султановна \\ К.филол.н., доцент, Грозненский государственный \\ нефтяной технический университет \\ имени академика М.Д. Миллионщикова \\ alkhastova@mail.ru
}

Аннотация: Настоящая работа является продолжением сопоставительнотипологического исследования чеченского языка в области фонетики. Цель статьи состояла в том, чтобы сопоставить интонационные группы чеченского и английского языков с помощью компьютерной программы Praat. Впервые проведен сопоставительный анализ синтагм современного чеченского и английского литературных языков на примере спектограмм повествовательных, вопросительных, побудительных и восклицательных предложений. Установлены типологические сходства и различия ритмико-интонационных групп чеченского (исходного) и английского (целевого) языков. Полученные данные будут способствовать правильному усвоению английской интонации носителями чеченского языка, могут стать основой для дальнейшей разработки вопросов чеченского и, в целом, нахского языкознания.

Ключевые слова: чеченский язык, английский, язык, интонационная группа, Praat, спектограмма, мелодика, сопоставительный аспект.

Работа построена по принципу сопоставительного анализа неродственных языков. В работе также проводится анализ типологических особенностей каждого из сопоставляемых языков, используется метод типологического сравнения и метод коррелятивного описания установления соответствий.

Научная новизна данного исследования определяется тем, что в нем впервые проведен сопоставительно-типологический анализ интонационных групп на примере повествовательных, вопросительных, побудительных и восклицательных предложений двух разносистемных языков: чеченского и английского.

Вопрос проведения сопоставительного анализа интонации чеченского и английского языков представляется актуальным для дальнейшей разработки вопросов чеченского и, в целом, нахского языкознания. Овладение правильной интонацией носителями чеченского языка важно при изучении фонетики английского языка в вузах Чеченской республики. Это определило выбор темы и ее актуальности. 
В отечественном языкознании основы изучения интонации были заложены В.А. Богородицким, Л.В. Щербой и другими исследователями.

В разработку фонетической системы нахских языков значительный вклад внесли Ю.Д. Дешериев, Д.С. Имнайшвили, К.Т. Чрелашвили, К.3. Чокаев, А.Д. Тимаев, Р.А-Х. Саламова, М.Р. Овхадов, А.И. Халидов и другие ученые-кавказоведы. Интонация чеченского языка все еще остается наименее изученной частью лингвистики.

Многочисленные зарубежные лингвисты занимались вопросами интонации: Leon and Martin (1970), Di Cristo (1975), Gibbon (1976), Bertinetto (1979), Rossi, Di Dristo, Hirst, Martin and Nishunurna (1981), Selkirk (1984), Cruttenden (1986), Ladd (1996), Cutler, Dahan and van Danselaar (1997), Hirst and Di Cristo (1998), Lacheret and Beaugendre (1999).

Интонация относится к просодическим элементам языка, и это явление сложное.

Основными составляющими интонации являются:

- тон (мелодика речи), осуществляется за счет повышения или понижения голоса;

- речевой ритм (наблюдается при чередовании ударных и безударных слогов);

- темп (быстрота или медленность высказывания);

- тембр голоса;

- фразовое и логическое ударение;

В настоящей статье рассматривается мелодика речи - повышение и понижение тона в повествовательных, вопросительных, побудительных и восклицательных предложениях чеченского и английского языков.

Передача смыслового оттенка фразы является основной функцией интонации, поскольку именно правильная интонация способствует восприятию собеседником настроения, чувств, эмоций говорящего.

При обучении фонетики иностранного языка необходимо уделять специальное внимание вопросам интонации, так как правильная интонация способствует более точной передаче сообщения, что, в свою очередь, будет способствовать более эффективному усвоению студентами интонационных особенностей изучаемого языка. Интонация, наряду со звуками, играет важную роль в процессе изучения основ второго, третьего языка, но, к сожалению, сравнительно мало внимания уделяется вопросам интонации при обучении фонетики английского языка в неязыковых вузах.
При сопоставительном анализе ритмико-интонационных синтагм чеченского и английского языков для измерения интонации была использована компьютерная программа Praat. Впервые спектральные исследования интонационных групп в современном чеченском литературном языке на примере повествовательных, вопросительных, побудительных и восклицательных предложениях были проведены автором настоящей статьи. [12, с.115-123].

Программа Praat была разработана в 2008 году кафедрой фонетики Амстердамского университета под руководством Boersma and Weenink, в качестве инструмента для измерения интонации. Одной из функций Praat является анализ спектрограмм, анализ высоты тона и интенсивности.

После записи предложений на чеченском и английском языках, которая была произведена автором статьи, программа Praat показывает экран с контуром основного тона произнесенного предложения, помимо указания основного тона, интенсивности и его продолжительности (начитанные тексты предложений были взяты из произведений чеченских и английских литературных классиков).

Рассмотрим спектограммы, полученные в результате записи повествовательных, вопросительных, побудительных и восклицательных предложений в чеченском и английском языках.

Повествовательное предложение в чеченском языке (дийцаран предложени):

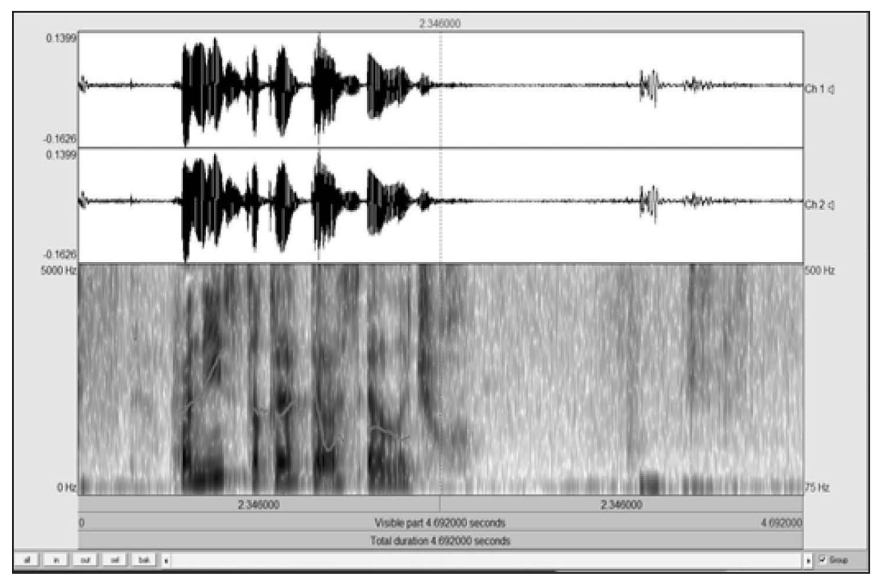

- Хьо нийса ча кхетта аса аьллачух,- корта ластийра Михаил Тариэловича. - Ты неправильно понял то, что я сказал,- помахал головой Михаил Тариэлович.[1, c.26].

На спектограмме показан подьем тона в начале и середине повествовательного предложения с постепенным нисхождением тона в конце предложения. 


\section{В английском языке:}

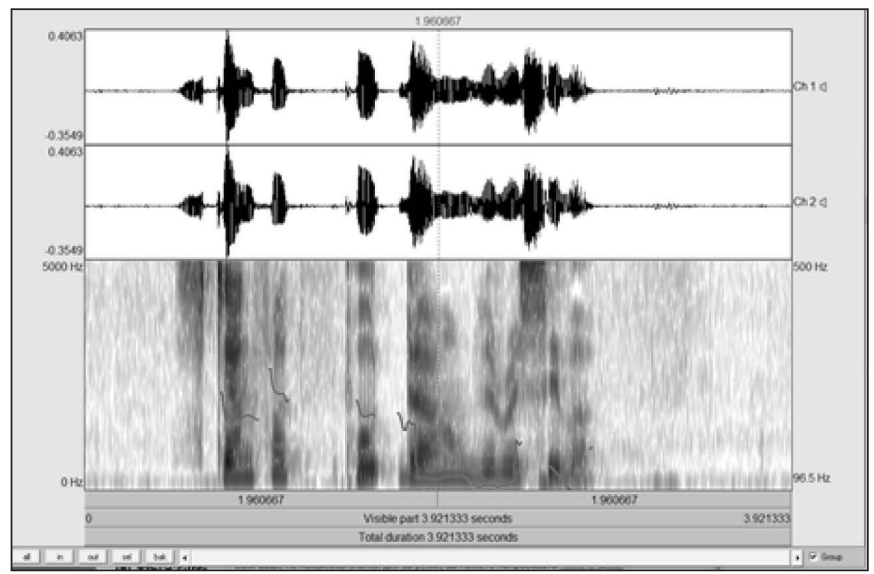

- Stanford put down the receiver. - Стэнфорд положил трубку. [10, с.29].

На спектограмме показан нисходящий тон (the Falling tone), который используется в английском языке в конце кратких повествовательного (declarative sentence) предложения, т.е. при утверждении.

Интонационно-вопросительное предложение в чеченском языке (интонаци-хаттаран предложени):

Вопрос в чеченском предложении выражается или интонационно, или особыми вопросительными словами и интонацией. Если вопрос выражен интонационно, то слово, которое выражает интересующую нас мысль, произносится более энергично, тоном вопроса.

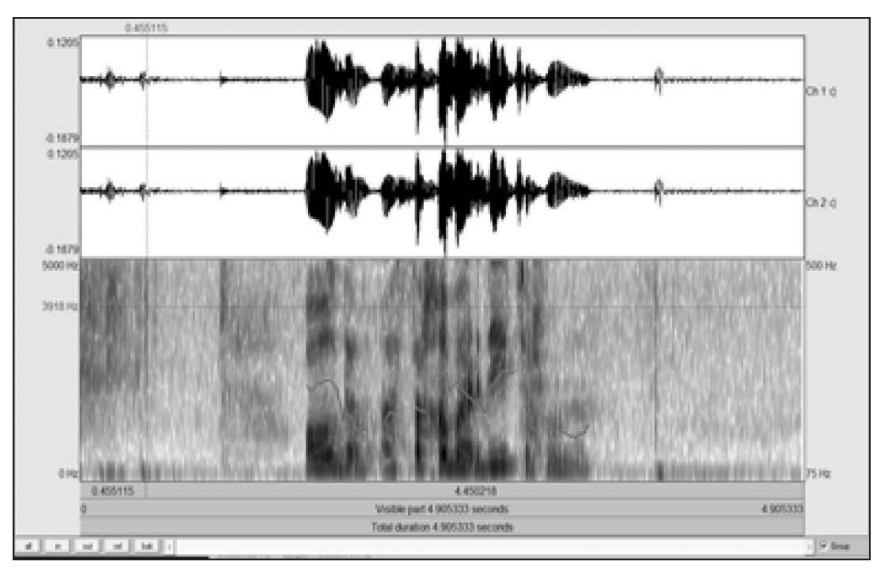

- ХІинца а могуш воцуш-х ца хиллий хьо?- Ты снова заболел что-ли? [3, с.6].

На спектограмме в начале предложения показана восходяще-нисходящая интонация и высокий подъем тона на предпоследнем слове с постепенным нисхождением тона в конце предложения.
В английском языке такому типу предложения соответствует общий вопрос:

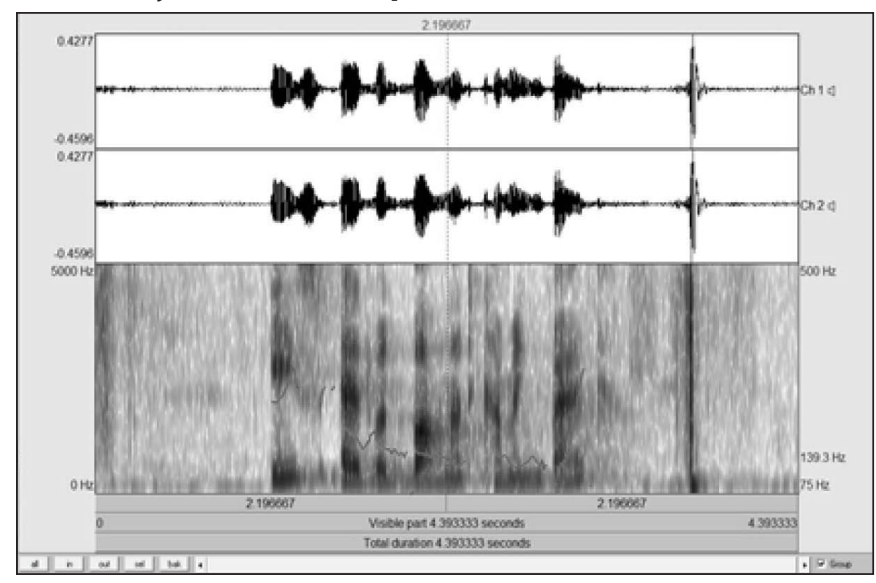

- Is Edward Barnard coming back? - Эдвард Барнет возврамается? [8, c.57].

На спектограмме показан восходящий тон (the Rising tone), который используется в английском языке в конце общего (general question) вопроса.

Вопросительное предложение в чеченском языке (хаттаран предложени):

В чеченском языке интонация в вопросительных предложениях может быть несколько слабее, если вопрос выражен вопросительным словом (местоимением, наречием). В чеченском языке имеются следующие вопросительные местоимения: мила? муьлш? - кто?; хlун? - что?; муьл ха? - какой? который?; маса? - сколько?; мел? - сколько?; масех, масийтта - несколько; муха? - как? каким образом?

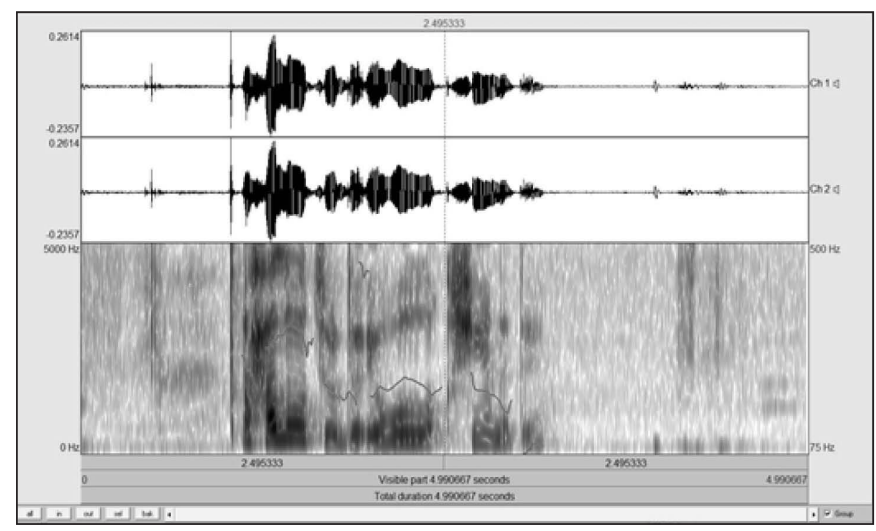

-Ткъа хьан лоцур ду и г1уллакх шена m1e? - Но, кто возьмет это дело на себя? [1, с.37-38].

На спектограмме в начале предложения показан высокий подъем тона с постепенным нисхождением тона в конце предложения. 
В английском языке данному типу вопроса соответствует специальный вопрос:

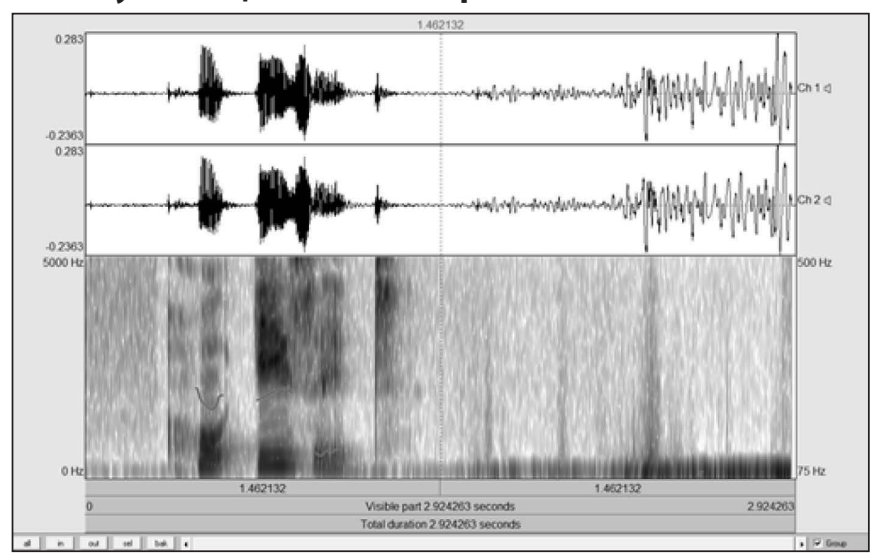

- Who is it? - Kmo эmo? [5, c.115].

На спектограмме показан нисходящий тон, который используется в английском языке в конце специального (special question) вопроса.

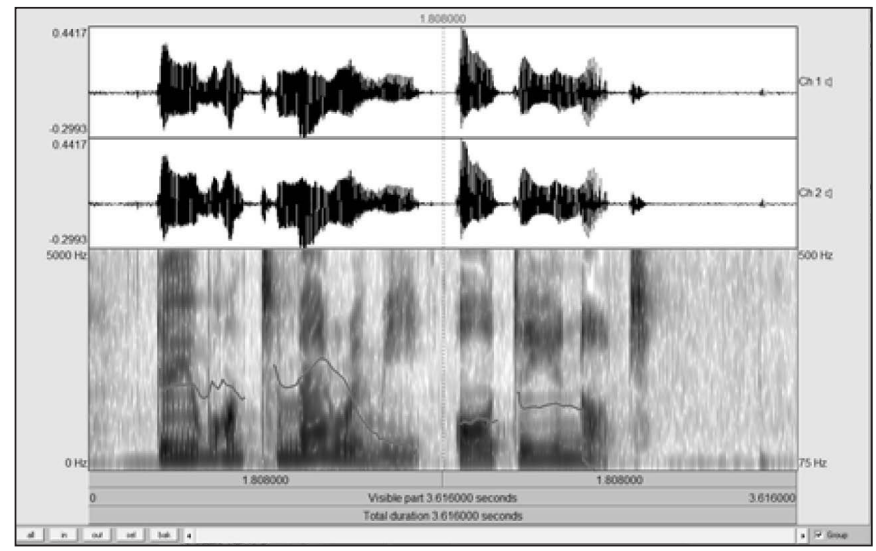

- Do you want to marry me or do you not? - Ты хочешь жениться на мне или нет? [8, с.19].

На спектограмме показан постепенный подъем тона в середине альтернативного (alternative question) вопроса с постепенным нисхождением тона в конце предложения.

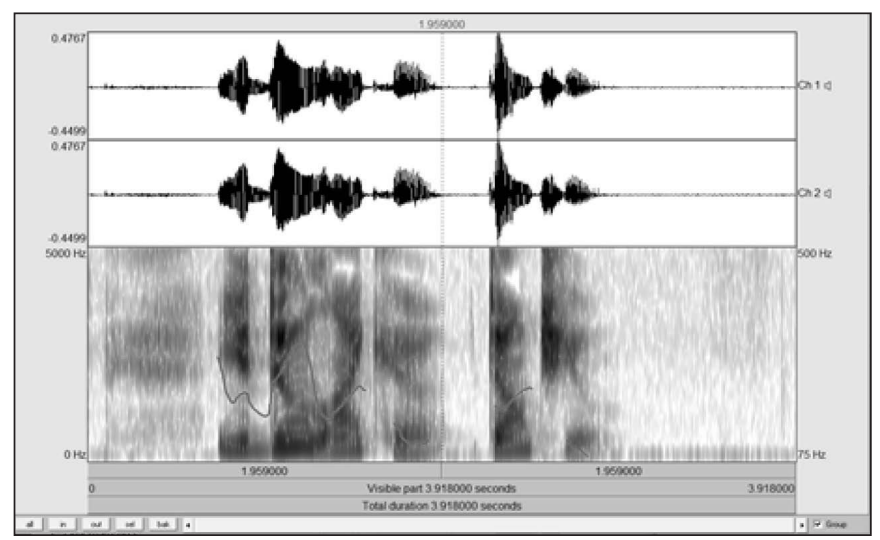

-You do like her, don't you? - Тебе она нравится, не так ли? [8, с.16].

На спектограмме показан восходящий тон, который используется в английском языке в конце разделительного (disjunctive question) вопроса.

Побудительное предложение в чеченском языке (тІедожоран предложени):

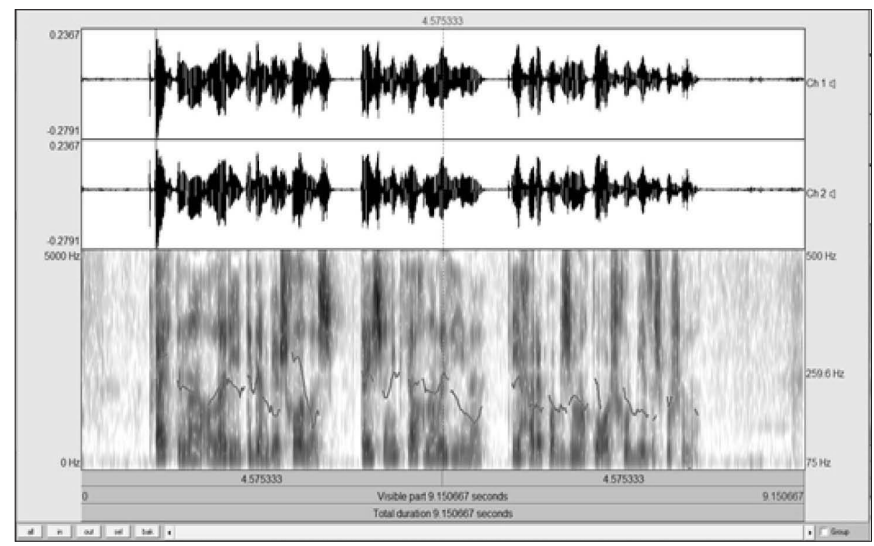

- Къаьсттина ларий тидам беш хилалаш, тайшаниг селхана лазийна, m1 ехьара ког жимма кхоош хила безаш бу шуна. - Серый вол вчера поранил заднюю ногу, имейте это ввиду, будьте особенно внимательны. [9, с.250].

На спектограмме в начале предложения показана нисходяще-восходящая интонация с постепенным нисхождением тона в конце предложения.

В чеченском языке вместо слова «пожалуйста» используется интонация. В зависимости от интонации одно и то же предложение можно произнести в приказном тоне, или в просящем.

\section{В английском языке:}

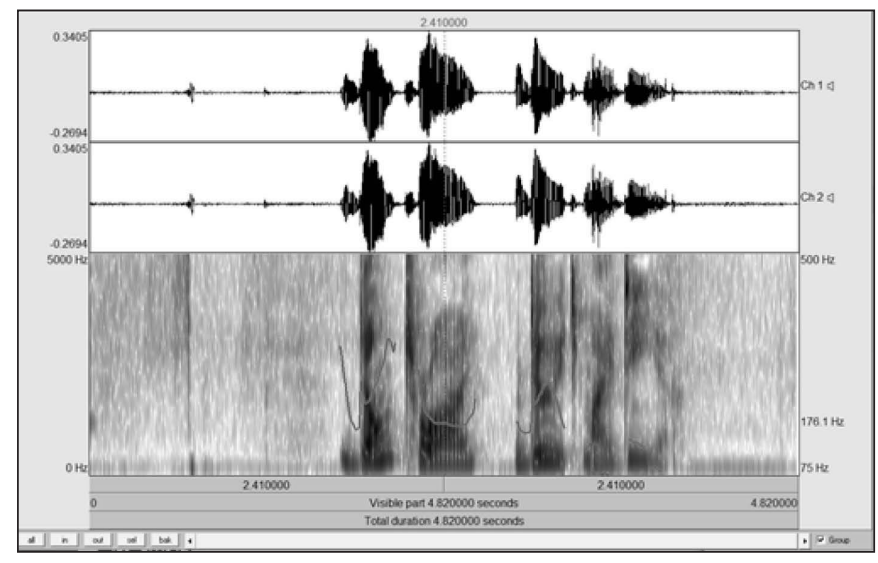

- Don't try. Do it, my dear. - Не пробуй (не пытайся). Сделай это, моя дорогая. [10, с.29].

На спектограмме показан нисходящий тон в конце побудительного предложения (imperative sentence): 
Восклицательное предложение в чеченском языке (айдаран предложени):

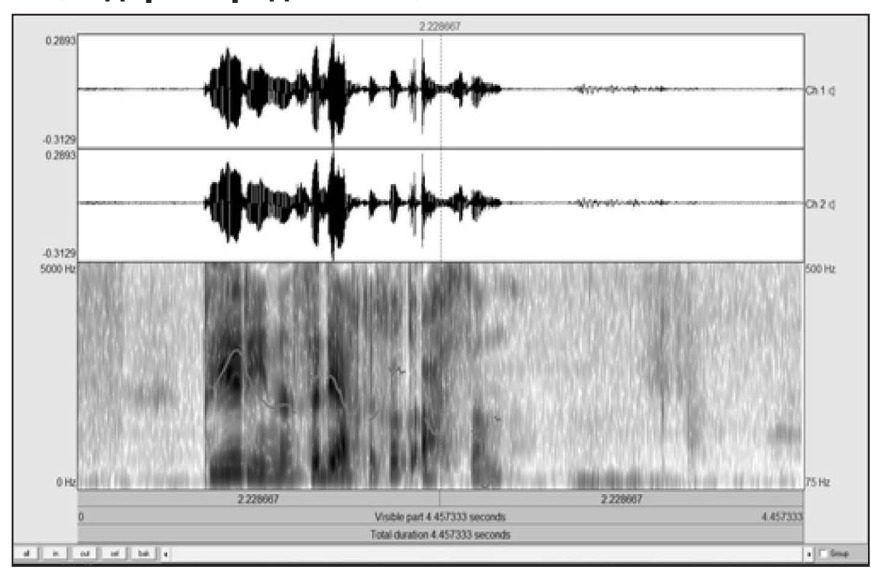

- Кхерийна са даьккхикха ахьа сан! - Ой, как ты меня напугал! [9, с.15].

На спектограмме показана восходяще-нисходящая интонация в начале предложения и слабый подъем тона на предпоследнем слове с постепенным нисхождением тона в конце предложения.

\section{В английском языке:}

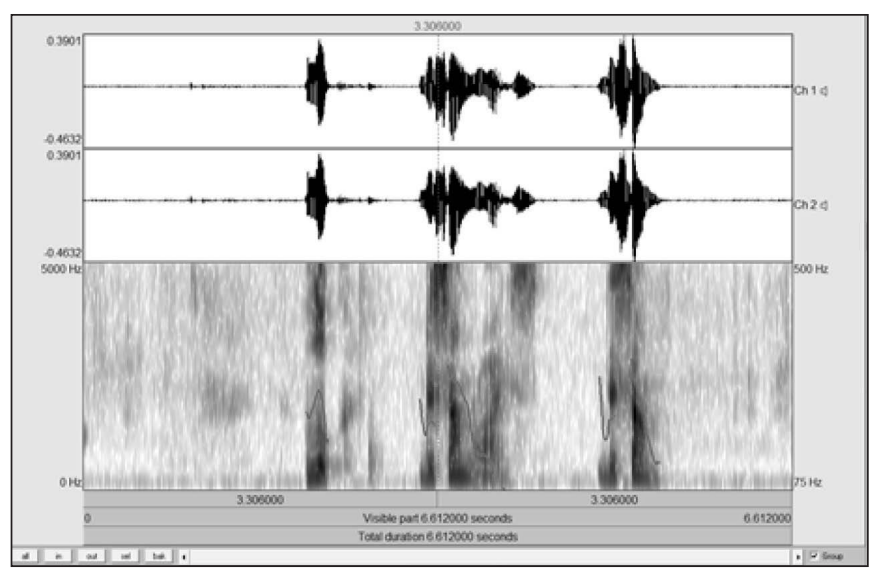

- Look! The sunrise! The sun! - Посмотри! Восход! Солнue! [11, c.18].

На спектограмме показан нисходящий тон, который используется в английском языке в конце восклицательного предложения (exclamatory sentence).

Проведенный сопоставительный анализ интонационных групп в повествовательных, вопросительных, побудительных и восклицательных предложениях в чеченском и английском языках позволил выявить ряд закономерностей, характерных для сопоставляемых языков, а также описать их интонационные различия.

В повествовательных, вопросительных, побуди- тельных и восклицательных предложениях в чеченском и английском языках используется нисходящая интонация.

В интонационно-вопросительном предложении в чеченском языке используется нисходящий тон в конце предложения в отличие от английского языка, где в соответствующем вопросе (общий тип вопроса) используется восходящая интонация.

Осознание фонетических различий между этими двумя языками важно для носителей чеченского языка, изучающих английский язык, для овладения правильной интонацией.

Сопоставительный подход к исследованию различных типов предложений на материале двух языков дал возможность ответить на вопрос, одинаков ли набор акустических средств в противопоставлении коммуникативных подтипов и акцентных структур в чеченском и английском языках.

В соответствии с тем, что обсуждалось выше, можно сделать вывод о том,

что знание английской интонации носителям чеченского языка позволит избежать недопонимания, поскольку интонация родного языка воздействует на интонацию изучаемого языка. От участников иноязычного диалога с носителями языка вряд ли может ускользнуть неуловимый смысл, передаваемый неизвестными им интонационными средствами. Общеизвестно, как трудно, например, уловить на чужом языке шутку или иронию, выразить оттенки удивления, раздражения, недоверия и т.д., которые часто передаются интонацией. Человек может безукоризненно владеть лексикой и грамматикой изучаемого языка, но делать ошибки в интонации, из-за чего рискует быть непонятым в обычных речевых ситуациях [7, с.78].

В данной работе впервые было проведено сопоставительно-типологическое исследование интонационных групп чеченского и английского литературных языков на примере повествовательных, вопросительных, побудительных и восклицательных предложений, проанализированы и обобщены результаты этого исследования; выделена и описана мелодика коммуникативных типов предложений при помощи современной компьютерной программы Praat.

Результаты исследования могут найти применение при обучении английскому произношению студентов - носителей чеченского языка, в курсе общей фонетики и фонетики чеченского языка, при создании учебных программ и пособий по английской фонетике в университетах Чеченской республики. 


\section{ЛИТЕРАТУРА}

1. Айдамиров А.А., «Еха буьйсанаш» - «Долгие ночи» роман, М.: Советский писатель, 1972.-158с.

2. Алироев И.Ю., Тимаев А.Д., Овхадов М.Р., Введение в нахское языкознание. Грозный -1998. - 106с.

3. Бадуев С-С.С., «Олдам» рассказы и повести, Грозный : Чеч.-Инг. кн. изд-во, 1989.-284с.

4. Дешериев Ю.Д. Современный чеченский литературный язык. Часть І: Фонетика. — Грозный, 1960 - 120 с.

5. Лондон Дж., «Adventure» - «Приключение», М.: Т8, 2016.- 240с.

6. Мациев А.Г. Чеченско-русский словарь. — М., 1961.

7. Марченко Е.В. Сравнительно-сопоставительный анализ интонационных групп английского и русского языков. Журнал Вестник, №2, МГГУ им. М.А. Шолохова, Sholokhov Moscow State University for the Humanities Филологические науки, М.: 2011. - (с.74-79).

8. Моэм У.С., Stories. - Рассказы, СПб., 2008.-160с.

9. Окуев Ш.Х., «Лай т1ехь ц1ен зезагаш»-»Красные цветы на снегу» Грозный: ГУП «Книжное издательство», 2008. - 276 с..

10. Шелдон С., «Morning, Noon and Night» - «Утро, полдень и ночь», Лондон, 2016.

11. Уэлс Г., «The first men in the Moon» - « Первые люди на луне», М.: 1947.

12. Alkhastova T.S., Experimental study of intonation groups of the modern Chechen literary language. Materials of the International Conference «Scientific research of the SCO countries: synergy and integration» - Reports in English (May 14, 2020.Beijing, PRC). ISBN 978-5-905695-56-8. Scientific publishing house Infinity, 2020. (c.115-123).

13. Hedberg N.\& Sosa J.M. The prosody of topic and focus in spontaneous English dialogue // Topic and Focus: Papers from a Workshop on Intonation and Meaning. Kluwer Academic Publishers. 2002.

14. Ladefoged, Р. Курс по фонетике . 5. ред. Оксфорд: Blackwell Publishing, 2006.

15. Rossi M., Intonation: Past, Present, Future. (Интонация: В прошлом, настоящем и будущем). In: Botinis A. (eds) Intonation. Text, Speech and Language Technology, vol 15. Springer, Dordrecht 2000, (pp.13-52).

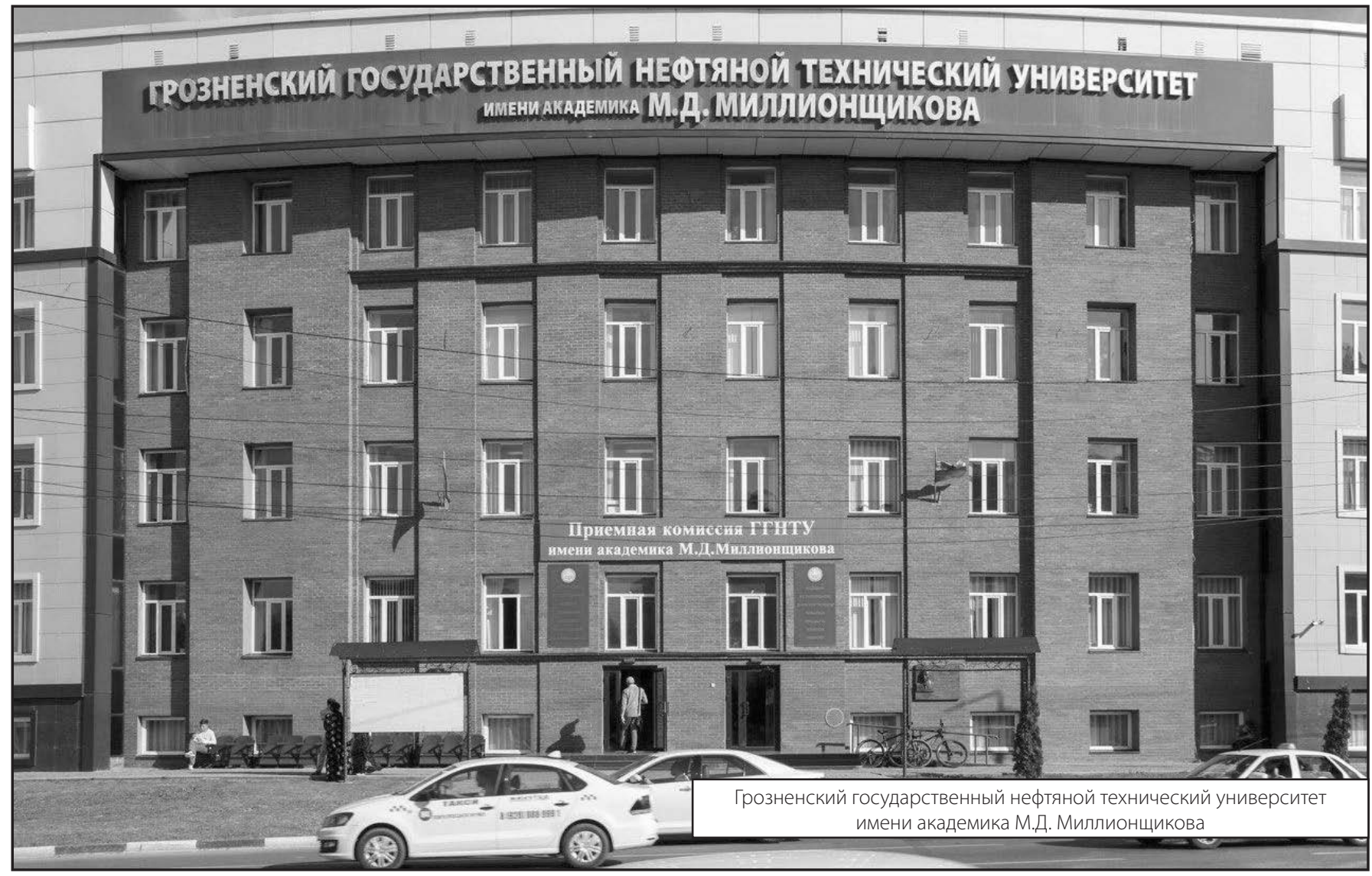

